\title{
Pink Filter: Gender Effects in Meaningful and Meaningless Product Differentiation
}

\author{
Camila Vincent de Urquiza and Alan Cooke \\ University of Florida
}

Faculty mentor: Alan Cooke, Warrington College of Business

\begin{abstract}
A simple Google search of the term "Pink Tax" pulls up thousands of results regarding "the cost of being a female consumer." There is a belief that women's products are priced more highly than men's products to reap the benefits of women preferring female-targeted products. We sought to determine the prevalence of these beliefs and the efficacy of such marketing practices. We consider the impact of both meaningful (e.g., different product features) and meaningless (e.g., labelling) differentiation on consumers' attitudes towards products. We propose that women have become skeptical towards meaningless product differentiation directed towards them. Whereas they respond favorably to products that target women through different ingredients and functionality, they respond more negatively to products that target women purely through packaging. We specifically looked at response to three products: sunscreen, razors, and protein bars and manipulated each product to isolate the effects of product features vs. the product advertising. Results were then measured to determine if different types of gender marketing affected women more strongly than they affected men. The results of this research have implications for product marketing campaigns and for public policy.

Keywords: pink tax, gender marketing, meaningful differentiation, meaningless differentiation
\end{abstract}

\section{Introduction}

Popular media frequently alludes to the Pink Tax, the phenomenon where products and services are inexplicably priced more highly when targeting women. However, there remains little detailed research on belief in or response to the phenomenon. Though gender targeting is a common way for marketers to achieve product differentiation, it is possible that marketers could abuse the practice by gender differentiating products when there is no concrete reason to do so. If marketers differentiate their products to add value for women, both marketers and consumers benefit. But if marketers modify products to create gender differences providing little actual benefit, women pay more but receive less value.

According to a 2015 study by New York's Department of Consumer Affairs which sampled 35 categories, women's products were more expensive 42 percent of the time compared to men's products, which were more expensive 18 percent of the time (New York City Department of 
Consumer Affairs 2015). The US Government Accountability Office conducted another study which found that, in 5 out of 10 categories studied, women's products were priced significantly higher than men's (Government Accountability Office 2018). Other research has shown that, for personal care products, women pay more on a per-ounce basis (Duesterhas, Grauerholz, Weichsel, Guittar 2011). That same study found that 85 percent of hair salons charged women more than men for basic haircuts, highlighting how price differences are not limited to products alone. In fact, the Consumer Federation of America found that women tend to receive more subprime mortgages when compared to men despite women and men having similar credit profiles, which highlights the breadth of the issue (Fishbein \& Woodall 2006).

Carpenter et. al. (1994) found that consumers utilize trivial attributes when they have no other means for product comparison. This is interesting because the Pink Tax phenomenon highlights the tendency to differentiate products through trivial attributes such as color to increase sales or prices. It is possible that gender targeting is effective due to its simplification of the decision making process. Mackenzie, Lutz \& Belch (1986) posit that an ad's qualitative factors may impact its efficacy. We believe it's possible that the effectiveness of gender targeting is affected by how meaningful the product's aspects are and by the consumer's belief in gender targeting as a deceptive practice. Shimp (1981) suggested that consumers' attitudes towards an ad may influence their feelings toward a product.

Gender-targeted marketing has been scrutinized for pandering to women. Poorly-received products include the "BIC For Her" pen in 2012 and Johnnie Walker's “Jane Walker" limited Scotch release in 2018, which was launched in conjunction with International Women's Day and Women's History Month. Given the recent increased attention surrounding the Pink Tax, we hypothesize that women may be primed to feel negatively towards products targeting them and exhibit a "pink filter." We are creating the term to describe a possibility where the use of femaletargeted marketing results in the opposite effect. In other words, customers like a product less when it looks or is female-targeted. Further, we posit that the "pink filter" may be exacerbated when the value provided is dubious. Of course, these effects may depend on whether product features are meaningfully differentiated and provide added value, or meaninglessly differentiated with no distinguishable difference from an otherwise neutral product. 


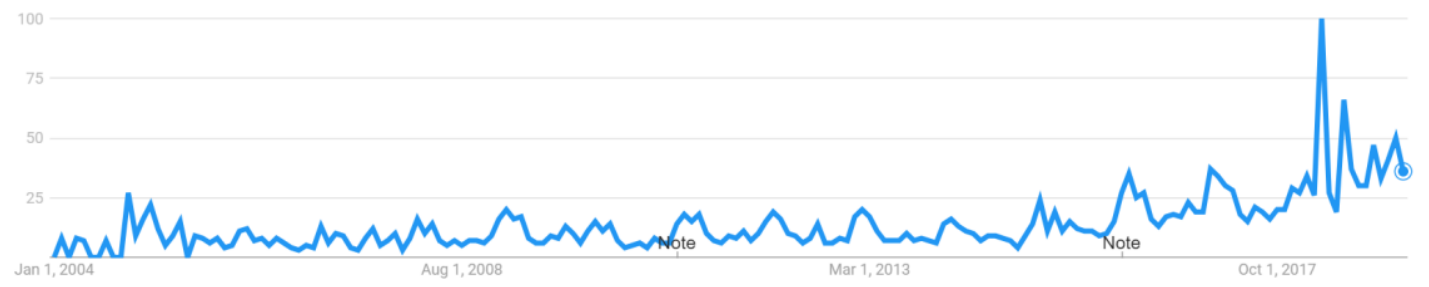

Figure 1. Google Trends results for the term "Pink Tax"

Over the past several years there has been a sharp increase in searches for the "Pink Tax," as evidenced by the Google Trends results for the phrase seen in Figure 1. In the last 15 years, awareness of the Pink Tax phenomenon has grown, and has gained so much traction that legislation has been proposed combatting the issue, though few laws have actually passed (Bessendorf \& Gans 2015). Despite this, New York City, Miami Dade county in Florida, and the state of California all prohibit gendered pricing for services (Cone, n.d.). Given the controversy, we aim to investigate the prevalence of beliefs about gender-targeting, and how effective such targeting may be. We seek to test whether men and women hold similar beliefs regarding genderbased targeting and whether they respond similarly to the practice. Further, we want to explore the relative effectiveness of different differentiation methods including those that differentiate based on functional, credence, and non-functional attributes.

\section{Methods}

Our methods include a survey assessing current perceptions of gender targeting, and two experiments evaluating responses to different forms of gender targeting. To explore the possibility that women are alienated by gender targeting, we conducted two experiments that manipulated the types of targeting used by different products.

\section{Survey}

A survey was created and designed to examine existing beliefs related to gender targeting and product differentiation through a series of attitudinal questions on a 7-point likert scale. These questions help to establish a baseline for how male and female participants view marketing practices. As well, they provide insight into participants' understanding of gender targeted product differentiation. The survey was unique to this project and has not been used in other work. 


\section{Procedure}

Subjects self-selected into the study through recruitment ads posted on Facebook and through Amazon mTurk. They were asked to rate their agreement with thirteen statements that assess responses to differentiation strategies on a +3 (strongly agree) to -3 (strongly disagree) scale. Each respondent was paid $\$ 1.25$ for completing the approximately 8 -minute survey. Additionally, 100 participants were recruited through social media but did not receive any compensation for completing the survey.

\section{Participants}

447 mTurk workers completed the Qualtrics survey through the mLab mobile research platform (Cooke \& Zubcsek 2011). 547 participants completed the survey. 44 total participants were dropped for dubious responses. For the purpose of clarity, only participants identifying as male or female were analyzed, other responses were dropped due to small sample sizes. Further, participants who failed to correctly answer attention check questions were not included. Accepted participant demographics consisted of 293 (58\%) females and 212 (42\%) males of all races between the ages of 18 and 60 years old.

\section{Experiment 1}

Our first experiment tested consumer response to gender differentiation. We manipulated whether products were targeted towards men, women, or were untargeted in terms of either form (e.g., their packaging) or function (e.g., their ingredients). We hypothesized that women would be more receptive to function rather than form-based differentiation. Conversely, we predicted that men would be more receptive to products targeting their gender using either type of differentiation.

\section{Stimuli}

Seven conditions were created with a 3 x 2 design (type of differentiation vs. gender), including an additional untargeted condition. Within each condition, participants saw three product replicates: energy bars, razors, and sunscreens. Form differentiation was achieved by altering ads to include a targeted background including a male or female model (e.g., exercising at a gym) or a neutral background related to the product. Product packaging was altered through packaging color, labels, or the inclusion of gender-stereotyped icons (e.g., flowers for women, 
sports equipment for men). Functional differentiation was achieved by implying gender-specific ingredients or benefits in product taglines. Form differentiation did not include any direct statement of gender-specific benefits, nor did it affect the form of the product itself. A similar approach was taken by Carpenter, Glazer \& Nakamoto (1994) when they assessed consumer brand evaluation on multi-attribute products (down jackets) by utilizing a single meaningless attribute to "distinguish" one of the product options.

\section{Procedure}

Participants were randomly assigned to one of seven conditions where they saw each replicate in its packaging along with its ad copy in randomized order. Then, they rated their attitude towards the product on a -5 (Very Negative) to +5 (Very Positive) scale. After that, they rated their quality expectations for the product ( $1=$ Poor to $7=$ Excellent), purchase likelihood (1=Not at all Likely to $7=$ Very Likely). Then they reported their relative expected price on a scale of -3 (Much less than the typical product category) to +3 (Much more than the typical product category). They also rated their agreement with a series of fourteen statements designed to assess individual differences in response to differentiation strategies, all on a +3 (Strongly Agree) to -3 (Strongly Disagree) scale. Lastly, participants rated their purchase frequency for each category, responded to manipulation check questions, and answered a number of demographic questions including their self-reported gender.

\section{Participants}

379 US undergraduate students from a large southeastern university received extra credit for completing the Qualtrics survey in a shared lab setting. 2 participants who did not identify as male or female were dropped from the study due to the small sample size of other gender identifications. The remaining 375 participants consisted of 132 (35.2\%) males and 243 (64.8\%) females, ages 18-24 of all races.

\section{Experiment 2}

As in Experiment 1, we tested consumer response to gender differentiation through form (e.g., packaging) or function (e.g., ingredients); however, this experiment did not use gendered advertising models for differentiation. 


\section{Stimuli}

The same replicates were used as in Experiment 1. Form differentiation occurred through packaging changes and function differentiation occurred through tagline changes. To control for the effects that gendered models and backdrops may have caused in Experiment 1, the products in Experiment 2 did not include backgrounds.

\section{Procedure}

As in Experiment 1, participants were assigned to one of seven conditions and saw the products. Then, they answered the same series of questions, rating expected quality, purchase likelihood, and relative expected price. We used the same 3 (type of differentiation: form, function, both) by 2 (gender targeted: women or men) between-subjects design and included a final baseline contion without differentiation of either kind.

\section{Participants}

276 Amazon mTurk workers completed the Qualtrics survey using the mLab mobile research platform (Cooke \& Zubcsek 2011). Each was paid $\$ 0.75$ for completing the approximately 5minute study. One participant was dropped from analysis due to the small sample size of participants who did not identify as male or female. The remaining 275 participants were 122 (44.4\%) males and $153(55.6 \%)$ females.

\section{Results}

\section{Survey}

We found that on average, women $(\mathrm{M}=5.61, \mathrm{SD}=1.37)$ significantly agree that female-targeted products are priced higher than other products $(\mathrm{t}(285)=19.87, \mathrm{p}<.001)$. Men $(\mathrm{M}=4.63 \mathrm{SD}=1.51)$ also significantly agreed that women's products are priced higher than other products $(\mathrm{t}(209)=7.06$, $\mathrm{p}<.001)$. Men also report being significantly more likely to buy products marketed towards their gender $(M=4.68, \mathrm{SD}=1.57, t(209)=6.28, p<.001)$. However, women did not report being more likely to buy female-targeted products $(M=4.18, \mathrm{SD}=1.73, t(285)=1.76, p=0.08)$. 


\section{Experiment 1}

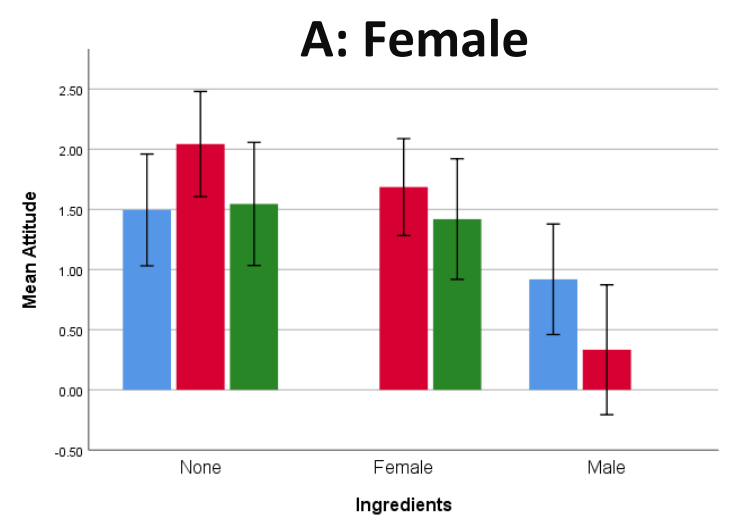

Error Bars: $95 \% \mathrm{Cl}$

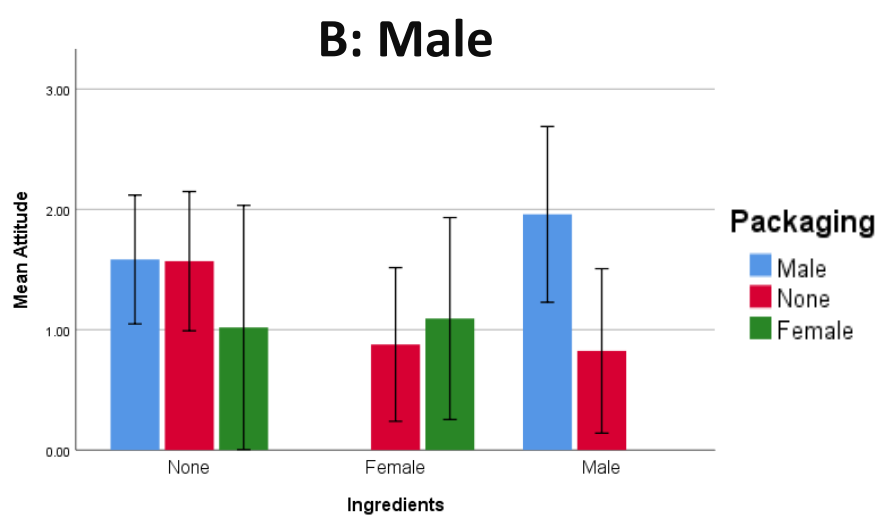

Error Bars: $95 \% \mathrm{Cl}$

Figure 2. Mean Product Attitude Ratings as a Function of Ingredients and Packaging

in Experiment 1.

Figure 2 shows the mean attitude ratings across product replicates as a function of ingredients and packaging. On average, women unsurprisingly reported lower attitudes towards products that target males than they do for non-targeted products $(F(1,236)=15.89, p<.001) .{ }^{1}$ More interestingly, womens' attitudes did not rise for products targeted towards their gender. Indeed, the average attitude across all female-targeting conditions was 1.55 , marginally less than in the untargeted condition $(\mathrm{M}=2.04, F(1,236)=3.02, p=.084)$. Pairwise contrasts were lower for all forms of female targeting, but only approached significance for the condition in which both types of female targeting were used $(F(1,236)=3.33, p=.069)$.

Additionally, male participants held lower attitudes towards products targeted to females than to untargeted products, although this difference did not reach statistical significance $(F(1,125)=2.49, p=.12)$. Men held marginally lower attitudes towards products that targeted them through ingredients only $(F(1,125)=2.51, p=.115)$, and showed no change in attitude for products that targeted them through packaging only $(F(1,125)=0.00, p=.97)$, or through both forms of targeting $(F(1,125)=0.10, p=.75)$.

\footnotetext{
${ }^{1}$ Pairwise contrasts showed that each male condition differed significantly from the baseline condition except for the male targeting by packaging, which was marginally significant $(F(1,236)=2.50, p=.116)$.
} 

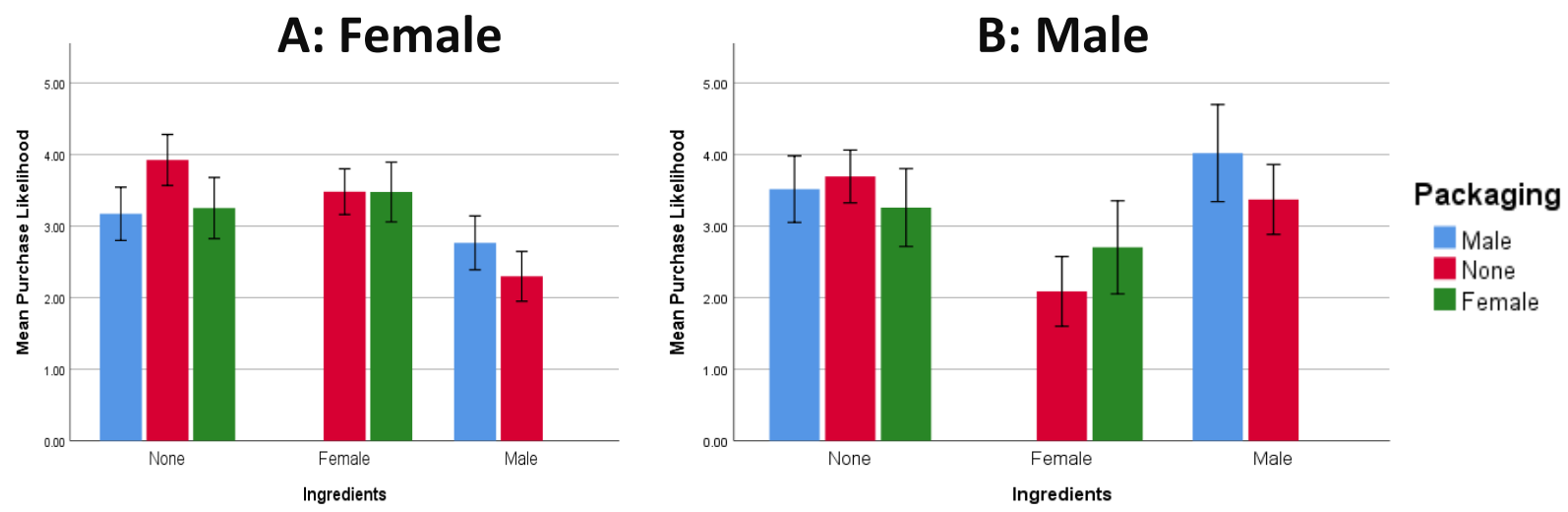

Figure 3. Mean Purchase Likelihood Ratings as a Function of Ingredients and Packaging in Experiment 1

Figure 3 shows mean purchase likelihood ratings across replicates. Both males and females rated their purchase likelihood differently across conditions $(F(6,125)=6.84, p<.001$ and $F(6,236)=8.42, p<.001$, respectively). Unsurprisingly, males rated their likelihood of buying a female-targeted product lower than that of a gender-undifferentiated product $(F(1,125)=8.83$, $p=.004$ ) and females rated their likelihood of buying a male-targeted product lower than a gender undifferentiated product $(F(1,236)=28.4, p<.001)$. Surprisingly, women also rated their purchase likelihood lower for female-targeted than untargeted products on average $(F(1,236)=5.50$, $p=.02$ ). Compared to an untargeted product, women rated their purchase likelihood for femaletargeted products marginally lower when targeting was done either by ingredients only $(F(1,236)=2.77, p=.097)$ or ingredients and packaging $(F(1,236)=2.80, p=.095)$, and significantly lower when it was done by packaging only $(F(1,236)=6.12, p=.014)$.

In contrast, men rated their likelihood of buying a male-targeted product the same as that of buying an untargeted product $(F(1,125)=0.05, p=.83)$. All pairwise contrasts were not significant (all $p \mathrm{~s}>.33$ ). On average, women rated their purchase likelihood lower for female-targeted than untargeted products $(F(1,236)=5.50, p=.02)$. Ratings of expected quality or price did not differ significantly across the conditions for either gender.

\section{Experiment 2}

Results aligned with those found in experiment 1. Figure 4 shows the mean attitude ratings across replicates as a function of ingredients and packaging. On average, women hold lower attitudes towards male-targeted products than those that are untargeted $(F(1,146)=5.91, p=.016)$. 
Furthermore, we again found that womens' attitudes did not increase for female-targeted products. In fact, the average attitude for female-targeting conditions was 2.32, which was not significantly less than the untargeted condition $(\mathrm{M}=2.44, F(1,146)=0.07, p=.79)$.

For men, average attitudes towards female-targeted products did not differ from attitudes towards neutral products $(F(1,115)=2.11, p=.149)$. All three female-targeted conditions were lower than the untargeted condition, but only packaging-only condition approached significance $(F(1,115)=3.36, p=.69)$. Likewise, men held the same attitude, on average, towards both targeted and untargeted products $(F(1,115)=1.63, p=.204)$. Although all male-targeted conditions showed lower mean attitudes, none were significant (all $p \mathrm{~s}>.14$ ).
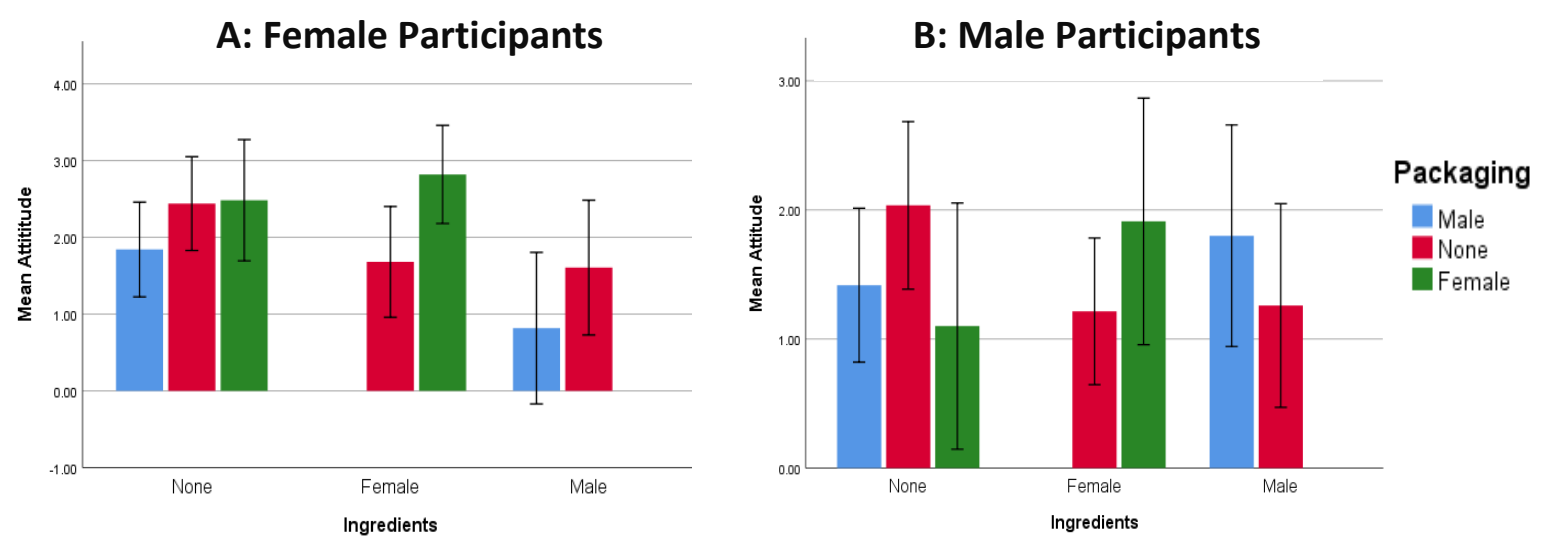

Figure 4. Mean product attitude ratings as a function of ingredients and packaging in Experiment 2.

Below, Figure 5 shows mean purchase likelihood ratings across replicates. Females rated their likelihood of purchase differently across conditions $(F(6,146)=3.44, p=.003)$, though this was only marginally significant for male participants $(F(6,115)=1.90, p=.087)$. Unsurprisingly, women $(F(1,146)=7.06, p=.009)$ and men $(F(1,115)=6.85, p=.01)$ rated their likelihood of buying a product targeted at the opposite gender lower than that of a neutral product. In contrast, both women and men's average ratings of products targeted towards their own gender did not differ from the respective untargeted products $(F(1,146)=0.10, p=.76$ and $F(6,115)=0.89, p=.35$, respectively). In both cases, each of the pairwise contrasts against the baseline was nonsignificant (all ps >.15). 

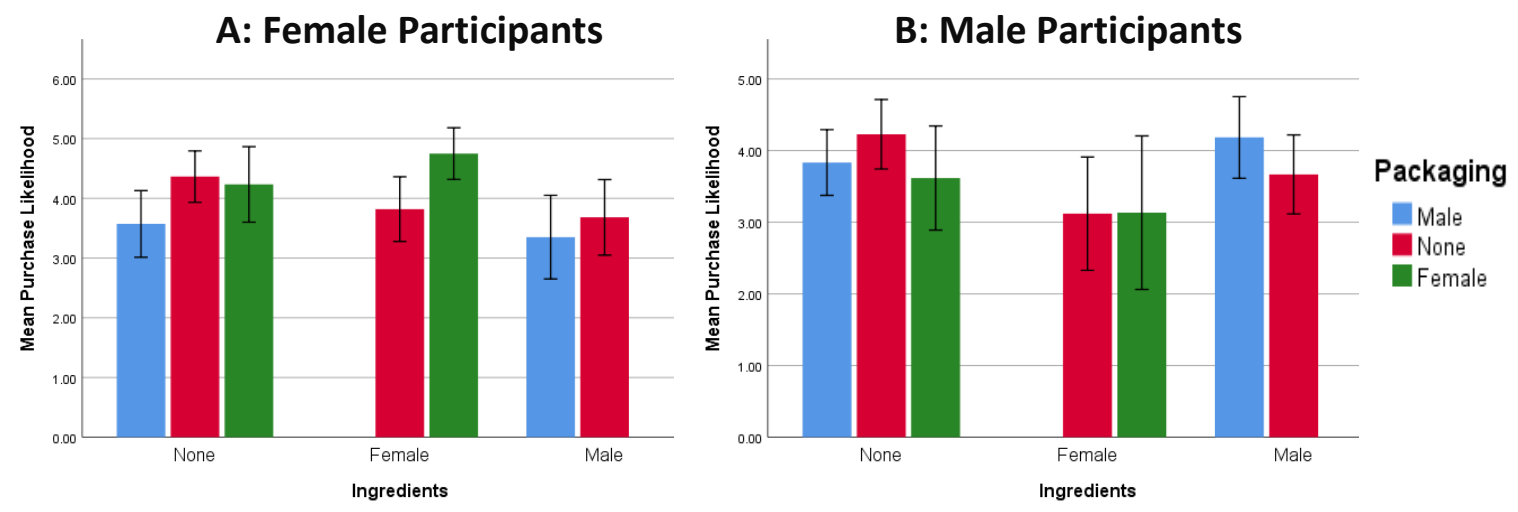

Figure 5. Mean purchase likelihood ratings as a function of ingredients and packaging in Experiment 2.

Ratings of expected quality did not differ significantly across the different conditions for men $(F(6,115)=0.53, p=.78)$ but did differ for women $(F(6,146)=2.39, p=.031)$. The difference for women stems from their rating the expected quality of male-both targeted condition $(\mathrm{M}=4.62)$ as lower than those in the female-packaging targeted condition $(\mathrm{M}=5.35)$. And as in experiment 1, expected price ratings did not differ across conditions for either males $(F(6,113)=1.05, p=.40)$ or females $(F(6,146)=1.79, p=.106)$.

\section{Discussion}

\section{Survey}

Results indicate belief that women's products are priced higher than non-gender-targeted products, consistent with the Pink Tax phenomenon. They further indicate that both men and women believe that prices increase for women's products. Finally, the finding that women are not more likely to buy women's products suggests that they may be skeptical of the benefits associated with such targeting.

\section{Experiment 1}

We found that whereas men appear to be unaffected, women tended to respond negatively to female-targeted products. The effect seems amplified when differentiation is based solely on packaging and imagery. In contrast, men appear unaffected by gender-targeted products of any form. They tended to respond to male-targeted products in the same way as they did untargeted products. Effects appear unrelated to perceptions of either expected quality or price, as neither factor varied systematically with condition. Experiment 1 could be skewed by the college student 
sample used which does not represent the broader population. Research shows that college students are younger, wealthier, and may be more skeptical of traditional advertising approaches (Obermiller \& Spangenberg 1998, 2000). It is possible that students have a more limited exposure to products in the marketplace, and that their exposure supports brands' dubious use of gender differentiation.

Alternatively, it is possible that older, more experienced consumers have experienced deceptive marketing practices but have either learned to avoid such brands or have simply become inured to the situation. A further limitation is that differentiation may have been confounded by the use of gendered models in addition to targeted packaging. Though realistic given traditional advertising practices, it does not allow us to say whether product packaging alone caused women to respond to female-targeted products more negatively. To allay these concerns, Experiment 2 utilized a more diverse and representative sample, and also paired products in their packaging with a stated benefit without including background images.

\section{Experiment 2}

Both studies indicated that gender-based differentiation tends to produce the same or lower attitudes and purchase intentions as for untargeted products. The results of Experiment 2 differ somewhat from those of Experiment 1. There are of course some key differences between the two experiments. For one, women rated their expected quality for the male-both targeted condition as lower than those for the female-packaging condition which was not seen in experiment 1. Also in Experiment 2, men showed lower mean attitudes for all male-targeted conditions, though none of these were found to be significant. However, both studies indicated that gender-based differentiation tended to have no effect on, and even occasionally decrease the attitudes and purchase likelihoods for members of the targeted groups. This result was seen for both male and female participants, and did not seem directly related to either quality or price inferences about the differentiated products.

\section{Conclusion and Future Research}

Our findings indicate that it is possible that a pink filter may exist as, on average, women were not significantly more positively responsive towards female-targeted products. We would like to look further into the possibility with different types of gender differentiation such as 
scents which are often stereotyped to fit gender stereotypes. Additionally, utilizing different replicates could allow for different results as a potentially confounding variable of our research is that participants may not have purchased or used the presented products frequently. This study is limited by the age of participants in Experiment 1. Due to the skew towards college-aged respondents, it is possible that our results are not representative of the broader population. Another limitation is the small array of products tested. By testing more products, there could be different responses to the type of product manipulated. Future research could explore the possibility of different subsets of women who respond differently to gender-targeted marketing. For example, while it may be effective for those who prefer it, some may be entirely turned off by the practice. Furthermore, there could be additional research to understand if a corresponding male "blue filter" equivalent exists. Additional studies may be able to highlight mens' responses to male-targeted products to determine if that sort of differentiation results in positive or negative responses. Finally, if the context in which a product is shown affects how consumers perceive it, research could be conducted in other areas, such as with technology and gaming cables which can be marketed differently depending on their intended use.

\section{Acknowledgements}

I would like to express my sincere thanks to my mentor for his assistance, mentorship, time, and constructive feedback throughout the planning, organization, and carrying out of this project. I would also like to thank my peers for their assistance in data analysis and collection. I am grateful for Dr. Anne Donnelly and the Center for Undergraduate Research for developing the University Scholars Program and making this research possible. Finally, I would like to thank my parents for their support during my studies.

\section{References}

Bessendorf, A., \& Gans, S. (2015). From Cradle to Cane: The Cost of Being a Female Consumer (pp. 176, Rep.). New York City, New York: New York City Department of Consumer Affairs.

Carpenter, G. S., Glazer, R., \& Nakamoto, K. (1994). Meaningful Brands from Meaningless Differentiation: The Dependence On Irrelevant Attributes. Journal of Marketing Research, 31(3), 339. doi: $10.2307 / 3152221$

Cone, Michael. (n.d.). Pink Tax FAQ. Retrieved from pink.tax

Cooke, Alan J., and Peter Pal Zubcsek (2011), “mLab: A Collaborative Mobile Research Lab,” Marketing Science Institute "Ideas Challenge" research proposal. 
Duesterhaus, M., Grauerholz, L., Weichsel, R., \& Guittar, N. A. (2011). The Cost of Doing Femininity: Gendered Disparities in Pricing of Personal Care Products and Services. Gender Issues,28(4), 175-191. doi:10.1007/s12147-011-9106-3

Fishbein, A. J., Woodall, P. (2006). Women are Prime Targets for Subprime Lending: Women are Disproportionately Represented in High-Cost Mortgage Market. Consumer Federation of America, Washington, DC

Government Accountability Office. (2018). Report: Consumer protection: Gender- related price differences for goods and services. US Fed News Service, Including US State News.

Mackenzie, S. B., Lutz, R. J., \& Belch, G. E. (1986). The Role of Attitude toward the Ad as a Mediator of Advertising Effectiveness: A Test of Competing Explanations. Journal of Marketing Research,23(2), 130-143. doi:10.1177/002224378602300205

Obermiller, C., \& Spangenberg, E. R. (1998). Development of a scale to measure consumer skepticism toward advertising. Journal of Consumer Psychology, 7(2), 159-186. doi:10.1207/s15327663jcp0702_03

Obermiller, C., \& Spangenberg, E. R. (2000). On the Origin and Distinctness of Skepticism toward Advertising. Marketing Letters, 24(2), 311-322.

doi:https://doi.org/10.1023/A:1008181028040

"Pink Tax" Data source: Google Trends (https://www.google.com/trends).

Shimp, T. A. (1981). Attitude toward the AD as a Mediator of Consumer Brand Choice. Journal of Advertising,10(2), 9-48. doi:10.1080/00913367.1981.10672756 